\title{
A STUDY ON THE CLINICAL AND ELECTRODIAGNOSTIC PROFILE OF GBS AND ITS CORRELATION WITH EARLY PREDICTORS OF PROGNOSIS
}

\author{
Anusuya Meganathan', Karthika Ramadoss ${ }^{2}$ \\ ${ }^{1}$ Assistant Professor of General Medicine, Institute of Internal Medicine, Madras Medical College and Rajiv Gandhi Government General \\ Hospital, Chennai. \\ 2Postgraduate Student, Department of General Medicine, Madras Medical College and Rajiv Gandhi Government General Hospital, \\ Chennai.
}

\section{ABSTRACT}

\section{BACKGROUND}

The purpose of this study is about the clinical profile with electrodiagnostic features of GBS in South Indian populations admitted at a tertiary care centre to correlate the clinical and electrodiagnostic features with disability of the disease and thereby to identify the poor prognostic clinical and nerve conduction features in a much earlier course of the disease.

\section{MATERIALS AND METHODS}

Cross-sectional study (prospective cum retrospective) done in patients with acute inflammatory demyelinating polyradiculopathy. Patients with other causes of weakness like hypokalaemic periodic paralysis, diphtheria, trauma, paraneoplastic condition and botulism were excluded. History for each patient was obtained through a questionnaire and further subject to thorough clinical examination. Apart from routine blood investigations, cerebrospinal fluid analysis and nerve conduction studies were also done for each patient.

\section{RESULTS}

In our study group of fifty patients with GBS, majority of patients belonged to the age group $20-40$ years, comprising $66 \%$. This correlates well with various GBS study groups conducted at NIMHANS, Kerala. The age and sex distribution did not seem to affe ct the outcome of the disease- death or degree of recovery with the p value being greater than 0.05 . The commonest subtype of GBS in our study population was demyelinating type comprising $60 \%$ and with axonal variants comprising $30 \%$. The Pong Kuohyo et al study group had $49 \%$ of the patients who were of demyelinating type. Cranial nerve involvement was present in $42 \%$ of the patients and the facial nerve paralysis was the most commonly observed palsy. Ito M Kuwabara et al found that the facial involvement is the most common, present in 70\%. Dysautonomia was present in $36 \%$ of the patients in our study population and it was directly related to ventilator dependence and mortality. Mechanical ventilation was required in $24 \%$ of the patients and the average duration of ventilator dependence was 14.5 days. Decreased CMAP $<10 \%$ was present in $18 \%$ of the patients. It had higher significance with morbidity and mortality with $\mathrm{p}$ value of $<0.001$.

Statistical Method- Data was analysed using SPSS (Statistical Package for Social Science) package.

\section{CONCLUSION}

GBS is the commonest cause of acute flaccid quadriparesis in our country. Our study group of 50 patients showed that axonal variant of GBS with cranial nerve involvement, dysautonomia, dependence on mechanical ventilation and decreased CMAP on nerve conduction study to be associated with higher mortality and morbidity in comparison to other parameters. Early identification of the above-mentioned adverse clinical and electrodiagnostic profile can be helpful in initiating prompt treatment and thereby attenuating the morbidity and mortality.

\section{KEYWORDS}

Guillain-Barre Syndrome (GBS), Dysautonomia, Mechanical Ventilation, Compound Muscle Action Potential (CMAP), Intravenous Immunoglobulin (IVIG).

HOW TO CITE THIS ARTICLE: Meganathan A, Ramadoss K. A study on the clinical and electrodiagnostic profile of GBS and its correlation with early predictors of prognosis. J. Evolution Med. Dent. Sci. 2017;6(24):2027-2032, DOI: 10.14260/Jemds/2017/442

\section{BACKGROUND}

Guillain-Barre Syndrome (GBS) is an acute, autoimmune, frequently severe, polyradiculoneuropathy. GBS affects all ages and it has a slight male preponderance. It is a

Financial or Other, Competing Interest: None.

Submission 15-02-2017, Peer Review 12-03-2017,

Acceptance 18-03-2017, Published 23-03-2017.

Corresponding Author:

Dr. Anusuya Meganathan,

\#351, Konnur High Road, C-47,

Sunnyvale Apartments,

Ayanavaram, Chennai-600023.

E-mail: anusuyarubi@gmail.com

DOI: $10.14260 /$ jemds $/ 2017 / 442$ symmetrical, predominantly motor, flaccid and areflexic paralysis with a clinical progression of the disease usually for a period of 4 weeks.

GBS has an incidence of around $0.4-1.9$ per one lakh population. The neuropathic symptoms are preceded by mild upper respiratory or gastrointestinal symptoms in most of the cases by 1 - 3 weeks in $50 \%-70 \%$ of cases. Recently, enteric organisms Campylobacter jejuni serological studies are done and it is identified as the causative organism in a small proportion of cases. Multiple cranial nerve palsy involving facial, bulbar and ocular muscle has been reported in $10 \%-60 \%$ of cases with papilloedema being uncommon. Respiratory failure occurs in $10 \%-30 \%$ of cases. 
GBS is a self-limiting disorder associated with recovery in up to $70 \%$ of cases, but the morbidity and mortality is also a concern as the sequelae of the disease is associated with significant motor handicap in up to $7 \%$ of cases. Mortality usually reaches up to $14 \%$ in few studies.

GBS subtypes are recognised on the basis of electrodiagnostic and pathologic distinctions and it included Acute Inflammatory Demyelinating Polyneuropathy (AIDP), the most common variant followed by two axonal variantsAcute Motor Sensory Axonal Neuropathy (AMSAN) and Acute Motor Axonal Neuropathy (AMAN). Regional variants include: 1. Miller Fisher syndrome; 2. Pandysautonomia; 3. Pure sensory syndrome, ophthalmoplegia with anti-GQ1b antibodies; 4. GBS with severe bulbar and facial palsy.

Cerebrospinal fluid analysis typically reveals albuminocytological dissociation. Nerve conduction studies shows reduced conduction velocity with conduction block, accompanied with increased distal latency. Prolonged or absent $F$ waves in two or more motor nerves is characteristically seen. Sensory nerve conduction delay occurs in up to $60 \%$ of cases. Immunomodulation is the treatment of choice, done with either plasmapheresis or Intravenous Immunoglobulin (IVIG) with both modes having equal efficacy in terms of treatment.

\section{Aims and Objectives}

The purpose of this study is about the clinical profile with electrodiagnostic features of GBS in a South Indian population admitted at a Tertiary Care Centre in Madras Medical College to correlate the clinical and electrodiagnostic features with disability of the disease and thereby to identify the poor prognostic clinical and nerve conduction features in a much earlier course of the disease, so that those groups can be treated and monitored more scrupulously during the course of the disease and hence attenuate the morbidity and mortality associated with the disease.

\section{MATERIALS AND METHODS}

This study was conducted after obtaining Ethical Committee approval and over a period of six months. Study population included patients admitted with GBS in medical wards and IMCU at our hospital. Sample size was around fifty cases of GBS and it is a cross-sectional study, which is both prospective and retrospective.

\section{Inclusion Criteria}

All cases were of acute inflammatory demyelinating polyneuropathy.

\section{Exclusion Criteria}

Hypokalaemic periodic paralysis, diphtheritic paralysis, trauma, paraneoplastic neuropathy, vasculitis, botulism, degenerative causes, ADEM, porphyria, infections like paraspinal abscess.

\section{Data Collection}

Informed consent was obtained from each patient or the relative. Patients had their history taken according to a Questionnaire and were subjected to clinical examination. Patients were subjected to routine blood investigations [renal function tests (including electrolytes), liver function tests], Electrocardiography, complete blood count, chest x-ray, HIV and HbsAg ELISA. Cerebrospinal fluid analysis done including CSF sugar, protein, LDH, cell count, cytology and cultures. Nerve conduction study analysis was done and the conduction velocity, latency, blocks, F waves, compound muscle action potentials were calculated.

Various parameters like age, sex, month of admission, preceding events, predominant symptoms, cranial nerve involvement, dysautonomia, requirement of mechanical ventilation, electrodiagnostic patterns, decreased compound muscle action potential less than 10 percent, CSF proteins, presence of albuminocytological dissociation, disability grading was done and was correlated with outcome of the disease depending on whether there is complete recovery of the disease, residual deficit or death.

\section{Statistical Methods}

Data was entered in MS Excel Spreadsheet and analysed using SPSS (SPSS Inc. Released 2009). PASW statistics for Windows Version 18.0 Chicago: SPSS Inc. Proportions were used. Chisquare test was used to measure association between variables.

\section{RESULTS}

The mean age group of our study population was 35.77 years. The respective age group related percentages are as follows; $38 \%$ of the patients were in the age group of 21 - 30 years; $28 \%$ belonged to the age group of 31 - 40 years; $20 \%$ in 41 50 years' age group; $8 \%$ belonged to the age group of $51-60$ years and $6 \%$ in 61 - 70 years; $66 \%$ of the patients were males and $34 \%$ females.

GBS cases occurred in maximum number during our study period of July comprising 36\%, August- 30\%, June$28 \%$, September- $6 \%$. The average duration of hospital stay was 21.2 days.

$22 \%$ of the patients had preceding events. RTI was present in $55 \%$ of the patients and AGE in $10 \%$ of the population.

The presenting symptom was lower limb weakness in $60 \%$ of the patients, sensory symptoms in $15 \%$ of the patients and upper limb weakness in $10 \%$ of the patients. $42 \%$ of the patients had cranial nerve involvement, $36 \%$ had dysautonomia and $24 \%$ requires mechanical ventilation in our study. The average duration of ventilator dependence was 14.5 days.

Average CSF protein was $76.03 \mathrm{mg} \%$. Albumin cytological dissociation was present in $78 \%$ of the cases.

Nerve conduction study revealed demyelinative type in $60 \%$ of the patients, AMAN variant in $22 \%$ of the patients, AMSAN variant in $10 \%$ of the patients and it was normal in $8 \%$ of the patients. Decreased CMAP $<10 \%$ was taken as a component of the nerve conduction study, as it was found to be a major determinant of prognosis in various randomised controlled study and it was found to be present in $18 \%$ of patients.

These patients were treated with plasmapheresis in 38\% of the cases and IVIG given in $62 \%$. The average latency for starting the treatment was 3.36 days; 5 patients (10\%) died in our study group and more than two-thirds of the patients were associated with dysautonomia and required mechanical ventilation. 
The Factors affecting the Outcome at Discharge both Morbidity and Mortality were found to be-

1. Presence of multiple cranial nerve involvement.

2. Requirement of mechanical ventilation.

3. Presence of dysautonomia.

4. Features of axonopathy- AMAN and AMSAN variant in nerve conduction study.

5. Decreased CMAP $<10 \%$ in nerve conduction study.

\begin{tabular}{|c|c|c|c|c|c|}
\hline \multirow{2}{*}{$\begin{array}{l}\text { Age in } \\
\text { Years }\end{array}$} & & \multicolumn{2}{|c|}{ Outcome } & \multirow{2}{*}{ Total } & \multirow{2}{*}{$\begin{array}{c}P \\
\text { value }\end{array}$} \\
\hline & & Death & Survive & & \\
\hline \multirow{3}{*}{$21-30$} & Count & 2 & 17 & 19 & \multirow{15}{*}{0.454} \\
\hline & $\begin{array}{c}\text { \% Within } \\
\text { Age in Years }\end{array}$ & $10.5 \%$ & $89.5 \%$ & $100.0 \%$ & \\
\hline & $\begin{array}{l}\text { \% Within } \\
\text { Outcome }\end{array}$ & $40.0 \%$ & $37.8 \%$ & $38.0 \%$ & \\
\hline \multirow{3}{*}{$31-40$} & Count & 2 & 12 & 14 & \\
\hline & $\begin{array}{c}\% \text { Within } \\
\text { Age in Years }\end{array}$ & $14.3 \%$ & $87.5 \%$ & $100.0 \%$ & \\
\hline & $\begin{array}{l}\text { \% Within } \\
\text { Outcome }\end{array}$ & $40.0 \%$ & $26.7 \%$ & $28.0 \%$ & \\
\hline \multirow{3}{*}{$41-50$} & Count & 0 & 10 & 10 & \\
\hline & $\begin{array}{c}\text { \% Within } \\
\text { Age in Years }\end{array}$ & $0 \%$ & $100.0 \%$ & $100.0 \%$ & \\
\hline & $\begin{array}{l}\text { \% Within } \\
\text { Outcome }\end{array}$ & $0 \%$ & $22.2 \%$ & $20.0 \%$ & \\
\hline \multirow{3}{*}{$51-60$} & Count & 0 & 4 & 4 & \\
\hline & $\begin{array}{c}\% \text { Within } \\
\text { Age in Years }\end{array}$ & $0 \%$ & $100.0 \%$ & $100.0 \%$ & \\
\hline & $\begin{array}{l}\text { \% Within } \\
\text { Outcome }\end{array}$ & $0 \%$ & $8.9 \%$ & $8.0 \%$ & \\
\hline \multirow{3}{*}{$61-70$} & Count & 1 & 2 & 3 & \\
\hline & $\begin{array}{c}\% \text { Within } \\
\text { Age in Years }\end{array}$ & $33.3 \%$ & $66.7 \%$ & $100.0 \%$ & \\
\hline & $\begin{array}{l}\text { \% Within } \\
\text { Outcome }\end{array}$ & $20.0 \%$ & $4.4 \%$ & $6.0 \%$ & \\
\hline
\end{tabular}

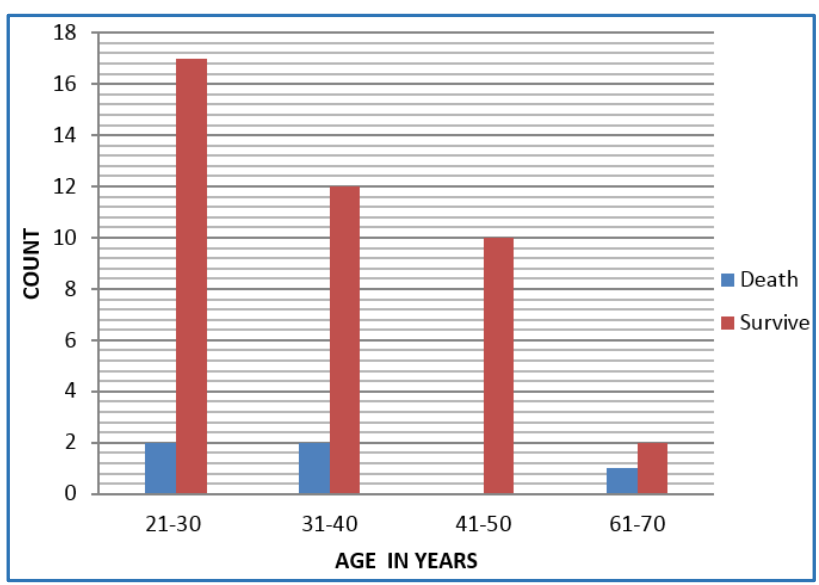

Figure 1. Age Distribution and Outcome (Death)
In our age group, the relationship between age and outcome (death) is insignificant with the p value of 0.454 .

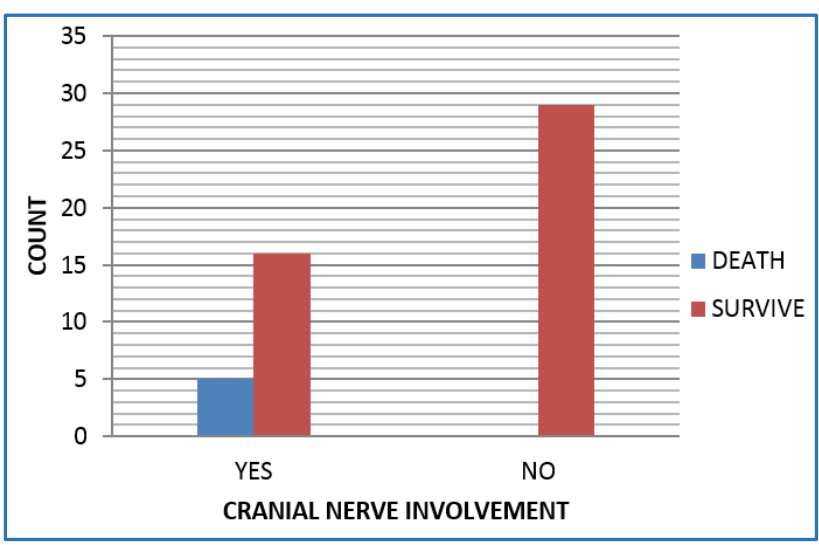

Figure 2. Cranial Nerve involvement and Mortality

Cranial nerve involvement was found to have significant relationship with outcome of death of the patient. $\mathrm{P}$ value 0.010- highly significant.

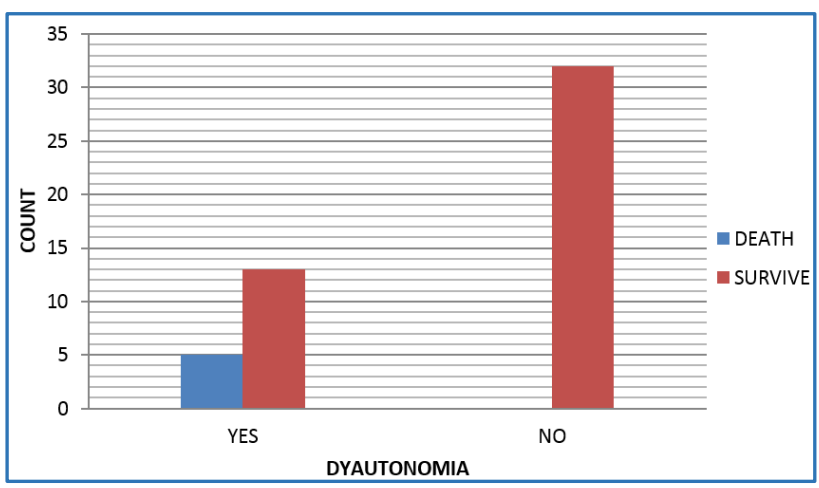

Figure 3. Dysautonomia and Mortality

Dysautonomia and mortality had strong correlation with the $\mathrm{p}$ value $=0.004$.

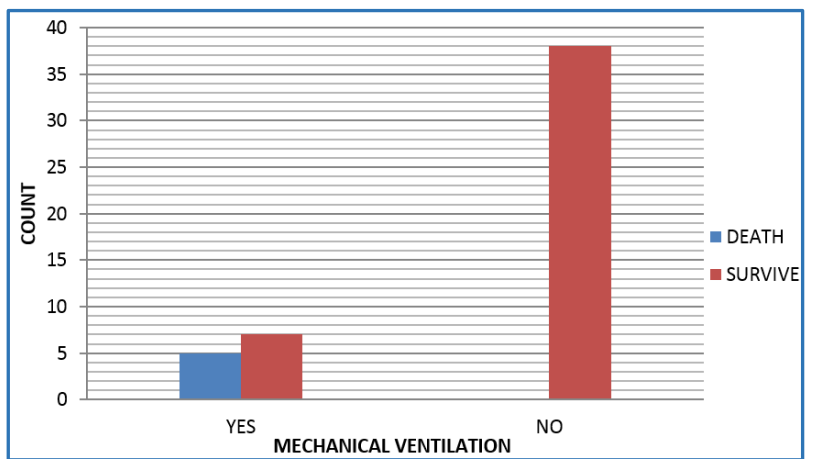

Figure 4. Mechanical Ventilation and Mortality

Mechanical ventilation had a very high significance with the mortality of the disease with $p$ value being highly significant of $<0.001$. 


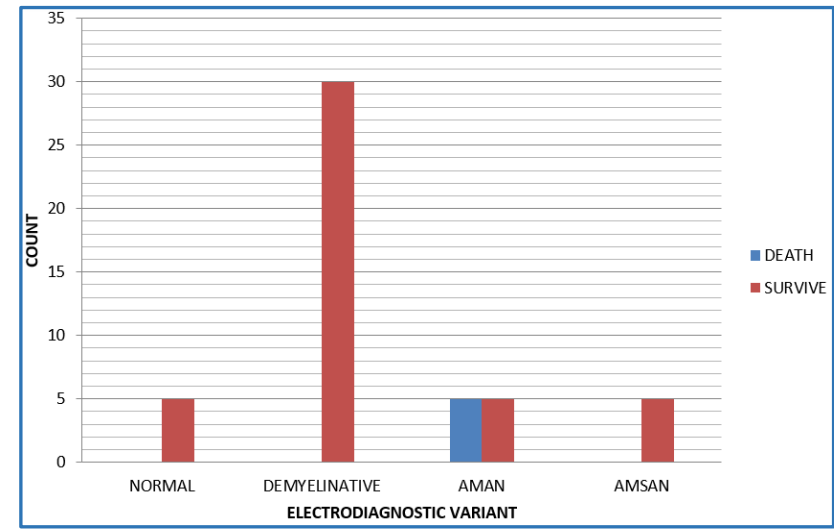

Figure 5. Electrodiagnostic Variant and Mortality

The electrodiagnostic variants of AMAN and AMSAN had significant relationship with outcome, $\mathrm{p}$ value $=<0.001$.

\begin{tabular}{|c|c|c|c|c|c|c|}
\hline & \multicolumn{3}{|c|}{ Outcome } & \multirow{2}{*}{$\begin{array}{c}P \\
\text { value }\end{array}$} \\
\hline & & & Death & Survive & Total & \\
\hline \multirow{6}{*}{$\begin{array}{c}\text { Decreased } \\
\text { CMAP } \\
<10 \% \text { of } \\
\text { Lower } \\
\text { Limit }\end{array}$} & \multirow{3}{*}{ Yes } & Count & 5 & 4 & 9 & \multirow{9}{*}{0.000} \\
\hline & & \begin{tabular}{|c|}
$\%$ Within \\
Decreased \\
CMAP $<10 \%$ \\
of Lower \\
Limit \\
\end{tabular} & $55.6 \%$ & $44.4 \%$ & $100.0 \%$ & \\
\hline & & $\begin{array}{l}\text { \% Within } \\
\text { Outcome }\end{array}$ & $100.0 \%$ & $8.9 \%$ & $18.0 \%$ & \\
\hline & \multirow{3}{*}{ No } & Count & 0 & 41 & 41 & \\
\hline & & $\begin{array}{c}\text { \% Within } \\
\text { Decreased } \\
\text { CMAP }<10 \% \\
\text { of Lower } \\
\text { Limit }\end{array}$ & $0 \%$ & $100.0 \%$ & $100.0 \%$ & \\
\hline & & $\begin{array}{l}\text { \% Within } \\
\text { Outcome }\end{array}$ & $0 \%$ & $91.1 \%$ & $82.0 \%$ & \\
\hline \multirow{3}{*}{ Total } & & Count & 5 & 45 & 50 & \\
\hline & & \begin{tabular}{|c|}
$\%$ Within \\
Decreased \\
CMAP $<10 \%$ \\
of Lower \\
Limit \\
\end{tabular} & $10.0 \%$ & $90.0 \%$ & $100.0 \%$ & \\
\hline & & $\begin{array}{l}\text { \% Within } \\
\text { Outcome }\end{array}$ & $100.0 \%$ & $100.0 \%$ & $100.0 \%$ & \\
\hline
\end{tabular}

Decreased CMAP of $<10 \%$ of lower limit had significant correlation with outcome with $p$ value $=<0.001$.

\begin{tabular}{|c|c|c|c|c|c|c|}
\hline & \multicolumn{3}{|c|}{ Outcome } & \multirow{2}{*}{\begin{tabular}{|c}
$\mathbf{P}$ \\
value
\end{tabular}} \\
\hline & & & Death & Survive & Total & \\
\hline \multirow{6}{*}{$\begin{array}{l}\text { Treat- } \\
\text { ment } \\
\text { Given }\end{array}$} & \multirow{3}{*}{$\begin{array}{l}\text { Plasma- } \\
\text { pheresis }\end{array}$} & Count & 5 & 14 & 19 & \multirow{9}{*}{0.003} \\
\hline & & $\begin{array}{c}\text { \% Within } \\
\text { Treatment } \\
\text { Given }\end{array}$ & $26.3 \%$ & $73.7 \%$ & $100.0 \%$ & \\
\hline & & $\begin{array}{l}\text { \% Within } \\
\text { Outcome }\end{array}$ & $100.0 \%$ & $31.1 \%$ & $38.0 \%$ & \\
\hline & \multirow{3}{*}{ IVIg } & Count & 0 & 31 & 31 & \\
\hline & & $\begin{array}{l}\text { \% Within } \\
\text { Treatment } \\
\text { Given }\end{array}$ & $0 \%$ & $100.0 \%$ & $100.0 \%$ & \\
\hline & & $\begin{array}{l}\text { \% Within } \\
\text { Outcome }\end{array}$ & $0 \%$ & $68.9 \%$ & $62.0 \%$ & \\
\hline \multirow{3}{*}{ Total } & & Count & 5 & 45 & 50 & \\
\hline & & $\begin{array}{l}\text { \% Within } \\
\text { Treatment } \\
\text { Given }\end{array}$ & $10.0 \%$ & $90.0 \%$ & $100.0 \%$ & \\
\hline & & $\begin{array}{l}\text { \% Within } \\
\text { Outcome }\end{array}$ & $100.0 \%$ & $100.0 \%$ & $100.0 \%$ & \\
\hline
\end{tabular}

$\mathrm{p}$ value $=0.003$
Disability Scoring- Modified Disability Grading Scale for GBS

Grade 0- Normal functional state.

Grade 1- Able to run with minor signs and symptoms.

Grade 2- Able to walk $5 \mathrm{~m}$ independently.

Grade 3-Able to walk $5 \mathrm{~m}$ with aid.

Grade 4- Bed or chair bound.

Grade 5- Requires assisted ventilation.

\begin{tabular}{|c|c|c|c|c|c|c|}
\hline & & & \multicolumn{2}{|c|}{ Outcome } & \multirow{2}{*}{ Total } & \multirow{2}{*}{$\begin{array}{c}P \\
\text { value }\end{array}$} \\
\hline & & & Death & Survive & & \\
\hline \multirow{12}{*}{$\begin{array}{c}\text { Hughes } \\
\text { Disability } \\
\text { Grading } \\
\text { Score } \\
\text { at } 15 \\
\text { Days }\end{array}$} & \multirow{3}{*}{$\begin{array}{c}\text { Grade } \\
2\end{array}$} & Count & 0 & 4 & 4 & \\
\hline & & $\begin{array}{l}\text { \% within } \\
\text { Hughes } \\
\text { Disability } \\
\text { Grading } \\
\text { Score at } \\
15 \text { days }\end{array}$ & $0 \%$ & $100.0 \%$ & $100.0 \%$ & \\
\hline & & $\begin{array}{l}\text { \%within } \\
\text { outcome }\end{array}$ & $0 \%$ & $8.9 \%$ & $8.0 \%$ & \\
\hline & \multirow{3}{*}{$\begin{array}{c}\text { Grade } \\
3\end{array}$} & Count & 0 & 23 & 23 & \\
\hline & & $\begin{array}{l}\% \text { within } \\
\text { Hughes } \\
\text { Disability } \\
\text { Grading } \\
\text { Score at } \\
15 \text { Days }\end{array}$ & $0 \%$ & $100.0 \%$ & $100.0 \%$ & \\
\hline & & $\begin{array}{l}\text { \% Within } \\
\text { Outcome }\end{array}$ & $0 \%$ & $51.1 \%$ & $46.0 \%$ & \\
\hline & \multirow{3}{*}{$\begin{array}{c}\text { Grade } \\
4\end{array}$} & Count & 0 & 11 & 11 & \\
\hline & & $\begin{array}{l}\text { \% within } \\
\text { Hughes } \\
\text { Disability } \\
\text { Grading } \\
\text { Score at } \\
15 \text { days }\end{array}$ & $0 \%$ & $100.0 \%$ & $100.0 \%$ & 0.001 \\
\hline & & $\begin{array}{l}\% \text { within } \\
\text { outcome }\end{array}$ & $0 \%$ & $24.4 \%$ & $22.0 \%$ & \\
\hline & \multirow{3}{*}{$\begin{array}{c}\text { Grade } \\
5\end{array}$} & Count & 5 & 7 & 12 & \\
\hline & & $\begin{array}{l}\text { \% within } \\
\text { Hughes } \\
\text { Disability } \\
\text { Grading } \\
\text { Score at } \\
15 \text { Days }\end{array}$ & $41.7 \%$ & $58.3 \%$ & $100.0 \%$ & \\
\hline & & $\begin{array}{l}\text { \% Within } \\
\text { Outcome }\end{array}$ & $100.0 \%$ & $15.6 \%$ & $24.0 \%$ & \\
\hline \multirow{3}{*}{ Total } & & Count & 5 & 45 & 50 & \\
\hline & & $\begin{array}{l}\text { \% Within } \\
\text { Hughes } \\
\text { Disability } \\
\text { Grading } \\
\text { Score at } \\
15 \text { Days }\end{array}$ & $10.0 \%$ & $90.0 \%$ & $100.0 \%$ & \\
\hline & & $\begin{array}{l}\text { \% Within } \\
\text { Outcome }\end{array}$ & $100.0 \%$ & $100.0 \%$ & $100.0 \%$ & \\
\hline
\end{tabular}

Table 4. Hughes Disability Score at 15 Days and Mortality

\section{DISCUSSION}

Guillain-Barre Syndrome is the most common cause of acute and subacute flaccid quadriparesis. Its distribution and occurrence is worldwide and it does not have much seasonal variation and it affects both children and adult population with no sex predilection.

GBS is usually heralded by a preceding event of respiratory or gastrointestinal infection or immunisation, 
which precedes the disease process by 3 weeks in up to $61 \%$ of the cases. There are numerous diseases associated with GBS, viruses, bacteria, immunisation, trauma, surgery, connective tissue disorders and even pregnancy, which can be followed by acute inflammatory demyelinating polyneuropathy.

In our study group, the mean age of population is 35.77 years. The patients in the age group of $20-40$ years were maximum comprising of around $66 \%$. But in large scale prospective study done by the Italian GBS group comprising of 297 study population, maximum age group belonged to the older population of 55 years comprising of $46.8 \% .^{1}$ In the Indian subcontinent, various GBS study groups conducted at NIMHANS, Kerala and other South Indian counterparts correlated well with our study group with a maximum number of patients belonging to the $2^{\text {nd }}$ and $3^{\text {rd }}$ decades of life. As these study groups were smaller and due to our small sample size of 50 this age difference might have occurred, but the middle aged population is affected more when compared to the Western population.

The male: female ratio is 3: 2 , demonstrated by many large randomised controlled trials in our study group the ratio was 2: 1 with male population comprising of around $66 \%$ and female population is $34 \%$. Hughes et al study showed a male: female ratio of 1.5: 1 . The Neurology Society of Netherlands showed the same, while Alshekhelee et al group demonstrated 2: 1 ratio. ${ }^{2}$

The age distribution and the sex distribution did not seem to affect the outcome of the disease- death or the degree of recovery with the $\mathrm{p}$ value being greater than 0.05 .

In our study group, the maximum number of cases occurred in the period of July followed by June comprising of a total of $64 \%$ of the cases. Similar results were obtained in the GBS study group of China with slight increase during the summer. The Ho TW et al group 3 in Northern China reported an increased incidence of GBS in the summers and it has been associated with Campylobacter jejuni and other viral infections. The month of occurrence did not have any significance with the recovery or death of the patients. Similar pattern was observed by van Koningsveld et $\mathrm{al}^{4}$ on the Caribbean island during the years of 1996, but it has come down back to normal in 2006.

The most common preceding event in our study group was respiratory tract infection comprising of around $24 \%$ and $10 \%$ of the cases had preceding gastrointestinal infection. Koga M, Yuki et al ${ }^{5}$ in Japan observed cough (48\%) and sore throat (39\%) with nasal discharge (30\%) and diarrhoea present in $27 \%$ of the patients. The preceding events did not have significance on the morbidity, but the recovery rate had significance with preceding events.

The commonest subtype of GBS in our study population was demyelinating type comprising $60 \%$ with axonal variant comprising 30\%. There was no Miller-Fisher variant in our study population and $10 \%$ of the patients were normal. The Rong Kuo Lyu et al study group had $49 \%$ of the patients which were demyelinative, $4 \%$ axonal, $19 \%$ MFS and $28 \%$ are unclassified. Hughes et al study population showed a sensory motor form to be the most common axonal variant in the European and North American territory. Ho TW et al showed the axonal variants were around 5\% - 10\%.6 Similar results were obtained by McKhann GM et al and Griffin JW et al,7 the variants were found to affect the recovery and mortality of the patients with poor outcome and mortality observed in axonal variants compared to demyelinating variants in our study group with the maximum death in the acute motor axonal neuropathy.

Lower limb weakness was the commonest presenting symptom in $60 \%$ of the patients, sensory involvement in $30 \%$ of the patients and upper limb weakness was noted in $10 \%$ of the patients. In the Taiwan GBS study group by Rong Kuo Lyu et al, $60 \%$ has sensory involvement. In the Spanish study group by Sedano MJ et al $66.7 \%$ had sensory involvement. The presenting symptom did not have any effect on mortality, but recovery rate seemed to have significance with the presenting symptoms with those involving the lower limb and sensory symptoms as the initial symptoms seemed to have residual deficit.

Cranial nerve involvement was present in $42 \%$ of the patients in our study group and the facial nerve paralysis was the most commonly observed palsy followed by bulbar palsy and ocular palsy. The Spanish study group had $43.5 \%$ with cranial involvement; the Taiwan study group had $60 \%$ of the study population and cranial nerve involvement. Ito $M$, Kuwabara et $\mathrm{al}^{8}$ found that facial nerve involvement is most commonly present in $70 \%$ with bulbar and oculomotor nerves less affected. Bickerstaff's brainstem encephalitis was the striking feature of the above study group. Cranial nerve involvement seemed to have significant effect on mortality, ventilator dependence and residual deficits were more in our study group.

Dysautonomia was present in $36 \%$ of the patients in our study population and it was directly related to ventilator dependence and mortality in our study group. It occurred in less than two-third of the patients in our study population and this may be due to the smaller size of our study population. Singh NK et al, Moulin et al and Winer JB showed that arrhythmias are more prevalent in the group with dysautonomia. Sinus tachycardia was the most common dysautonomic feature in our study with fluctuating blood pressure. Dysautonomia was the major cause of mortality in our study group.

Mechanical ventilation was required in $24 \%$ of the patients in our study group. The average duration of ventilator dependence was 14.5 days in our study group. The Rong Kyo Lyu et al study group had $20.9 \%$ with ventilator dependence; 10 days was the average duration on ventilator. J. H. Rees et al study group ${ }^{9}$ showed $25 \%$ of the patients required mechanical ventilation, the study was conducted in South East England with average duration of 42 days. Mechanical ventilation was directly related to mortality and poor recovery in our study population.

Nerve conduction study was done and decreased compound muscle action potential was observed. Decreased CMAP $<10 \%$ was present in $18 \%$ of the patients. It had higher significance with morbidity and mortality with $\mathrm{p}$ value of $<0.001$. Similar results were obtained by the Spanish GBS group by Sedona MJ et al and Taiwan group by Rong Kuo Lyu et al ${ }^{10}$ Decreased CMAP is a significant electrodiagnostic finding, which has greater significance with recovery and mortality.

Albuminocytological dissociation was present in $78 \%$ of the patients and it had no significance with morbidity or mortality of the patients in our study group. The disability was calculated using Hughes disability score and it had 
greater value in the predictability of morbidity and mortality in our study group. It is a simple bedside analytical score comprising of 6 scores. Grade 0 is without symptoms, Grade 6 is death. Grade 1 and 2 with mild symptoms, Grade 3, 5 and 5 with progressive worsening of symptoms culminating in respiratory failure, moribund status and ventilator dependence. It is a reliable and quick bedside analytical index of prognosis observed by Hughes et al study group.

Plasmapheresis was used as the method of treatment in $19 \%$ of the patients and IVIG given to $62 \%$ of the patients. In our study group, the patients with severe debilitation symptoms were started directly on plasmapheresis in comparison to IVIG treated groups, hence mortality was found to be slightly higher in the plasmapheresis treated group. Hughes et al,11 Van der Meche et al ${ }^{12}$ and Plasma exchange/Sandoglobulin Guillain-Barre syndrome trial found no difference in the efficacy of plasmapheresis to IVIG and combination of both were not found to be helpful or better over the other.

\section{Limitation of the Study Group}

Small study group.

Absence of followup study.

\section{CONCLUSION}

Guillain-Barre syndrome is the commonest cause of acute flaccid quadriparesis in our country. Early identification of poor diagnostic factors is essential to predict the outcome of the disease in the affected population.

Our study was undertaken to study about the clinical and electrodiagnostic presentation in our South Indian population and to correlate them with prognosis of the patients.

Our study with a group of 50 patients showed that axonal variant of GBS with cranial nerve involvement, dysautonomia, dependence on mechanical ventilation and decreased CMAP on nerve conduction study to be associated with higher mortality and morbidity in comparison to other parameters.

Age of the patients, sex distribution, month of admission, preceding events of respiratory and gastrointestinal infections were not associated with mortality and morbidity of the patients with minimal effect of preceding infections on recovery of the patients.

Early identification of severely affected group with the above mentioned adverse clinical and electrodiagnostic profile can be helpful for prompt treatment, anticipation of complication and adequate rehabilitation of the patients and thereby attenuating the morbidity and mortality associated with the same.

\section{REFERENCES}

[1] Italian Guillan-Barre study group. The prognosis and main prognostic indicators of Guillain-Barre syndrome: a multi-centre prospectrive study of 297 patients. Brain 1996;119(Pt 6):2053-61.

[2] van Koningsveld R, van Doorn PA, Schmitz PI, et al. Mild forms of Guillain-Barre syndrome in an epidemiologic survey in the Netherlands. Neurology 2000;54(3):620-5.

[3] Ho TW, Mishu B, Li CY, et al. Guillaine-Barre syndrome in northern China. Relationship to campylobacter jejuni infection and anti-glycolipid antibodies. Brain 1995;118(Pt 3):597-605.

[4] van Koningsveld R, Rico R, Gerstenbluth I, et al. Gastroenteritis associated Guillain-Barre syndrome on the Caribbean island Curaco. Neurology 2001;56(11):1467-72.

[5] Koga M, Yuki N, Hirata K. Antecendent symptoms in Guillain-Barre synrome: an important indicator for clinical and serological subgroups. Acta Neurol Scand 2001;103(5):278-87.

[6] Ho TW, Willison HJ, Nachamkin I, et al. Anti-GD1a antibody is associated with axonal but not demyelinating forms of Guillain-Barre syndrome. Ann Neurol 1999;45(2):168-73.

[7] Griffin JW, Li CY, Ho TW, et al. Pathology of motorsensory axonal Guillain-Barre syndrome. Ann Neurol 1996;39(1):17-28.

[8] Ito M, Kuwabara S, Odaka M, et al. Bickerstaff's brainstem encephalitis and Fisher syndrome form a continuous spectrum: clinical analysis of 581 cases. J Neurol 2008;255(5):674-82.

[9] Lyu RK, Tang LM, Cheng SY, et al. Guillain-Barre syndrome in Taiwan- a clinical study of 167 patients. J Neurol Neuro Surg Psychiatry 1997;63(4):494-500.

[10] Rees JH, Thompson RD, Smeeton NC, et al. Epidemiological study of Guillain-Barre syndrome in south east England. J Neurol Neurosurg Psychiatry 1998;64(1):74-7.

[11] Hughes RA, Swan AV, Raphael JC, et al. Immunotherapy for Guillain-Barre syndrome: a systematic review. Brain 2007;130(Pt 9):2245-57.

[12] Merkies IS, Schmitz PI, Samjin JP, et al. Fatigue in immune-mediated polyneuropathies. European Inflammatory Neuropathy Cause and Treatment (INCAT) group. Neurology 1999;53(8):1648-54. 